\title{
Dietary Patterns Characterized by High Meat Consumption Are Associated with Other Unhealthy Life Styles and Depression Symptoms
}

\section{OPEN ACCESS}

Edited by:

Kelly Costello Allison,

Perelman School of Medicine,

United States

Reviewed by:

Ulrich Schweiger,

Lübeck University Medical School,

Germany

Rebecca L. Emery,

University of Pittsburgh,

United States

*Correspondence:

Helena Canhão

helena.canhao@nms.unl.pt

tThese authors have contributed equally to this work.

Specialty section:

This article was submitted to Eating Behavior,

a section of the journal

Frontiers in Nutrition

Received: 20 April 2017

Accepted: 29 May 2017

Published: 14 June 2017

Citation:

Gregório MJ, Rodrigues AM,

Eusébio M, Sousa RD, Dias $S$, André B, Grønning K, Coelho PS, Mendes JM, Graça P, Espnes GA, Branco JC and Canhão H (2017)

Dietary Patterns Characterized

by High Meat Consumption Are

Associated with Other Unhealthy Life

Styles and Depression Symptoms.

Front. Nutr. 4:25.

doi: 10.3389/fnut.2017.00025

\begin{abstract}
Maria João Gregório ${ }^{1,2,3,4 \dagger}$, Ana M. Rodrigues ${ }^{1,5,6 \dagger}$, Mónica Eusébio ${ }^{5}$, Rute Dinis Sousa ${ }^{1}$, Sara Dias ${ }^{1,2}$, Beate André ${ }^{7,8}$, Kjersti Grønning ${ }^{7,8}$, Pedro S. Coelho ${ }^{9}$, Jorge M. Mendes ${ }^{9}$, Pedro Graça ${ }^{3,4}$, Geir A. Espnes ${ }^{7,8}$, Jaime C. Branco ${ }^{1,5,10}$ and Helena Canhão ${ }^{1,5 *}$

'EpiDoC Unit, Centro de Estudos de Doenças Crónicas (CEDOC) da NOVA Medical School, Universidade Nova de Lisboa (NMS/UNL), Lisboa, Portugal, ${ }^{2}$ Escola Superior de Saúde do Instituto Politécnico de Leiria, Leiria, Portugal, ${ }^{3}$ Faculdade de Ciências da Nutrição e Alimentação da Universidade do Porto, Porto, Portugal, ${ }^{4}$ Programa Nacional para a Promoção da Alimentação Saudável, Direção-Geral da Saúde, Lisboa, Portugal, ${ }^{5}$ Sociedade Portuguesa de Reumatologia, Lisboa, Portugal, ${ }^{6}$ Rheumatology Research Unit, Instituto de Medicina Molecular, Lisboa, Portugal, 'Department of Public Health and Nursing, Faculty of Medicine and Health Sciences, Norwegian University of Science and Technology, Trondheim, Norway, ${ }^{8}$ NTNU Center for Health Promotion Research, Trondheim, Norway, ${ }^{9}$ NOVA Information Management School, Universidade Nova de Lisboa, Lisboa, Portugal, ${ }^{10}$ Serviço de Reumatologia do Hospital Egas Moniz - Centro Hospitalar Lisboa Ocidental (CHLO - E.P.E.), Lisboa, Portugal
\end{abstract}

Objective: We aimed to identify dietary patterns (DPs) of Portuguese adults, to assess their socioeconomic, demographic, lifestyle determinants, and to identify their impact on health.

Design: EpiDoC 2 study included 10,153 Portuguese adults from the EpiDoC Cohort, a population-based study. In this study, trained research assistants using computerassisted telephone interview collected socioeconomic, demographic, dietary, lifestyles, and health information from March 2013 to July 2015. Cluster analysis was performed, based on questions regarding the number of meals, weekly frequency of soup consumption, vegetables, fruit, meat, fish, dairy products, and daily water intake. Factors associated with DP were identified through logistic regression models.

Results: Two DPs were identified: the "meat dietary pattern" and the "fruit \& vegetables dietary pattern." After multivariable adjustment, women $(\mathrm{OR}=0.52 ; p<0.001)$, older adults $(\mathrm{OR}=0.97 ; p<0.001)$, and individuals with more years of education $(\mathrm{OR}=0.96$; $p=0.025)$ were less likely to adopt the "meat dietary pattern," while individuals in a situation of job insecurity/unemployment ( $\mathrm{OR}=1.49 ; p=0.013)$, Azores island residents $(\mathrm{OR}=1.40 ; p=0.026)$, current smoking $(\mathrm{OR}=1.58 ; p=0.001)$, daily alcohol intake $(\mathrm{OR}=1.46 ; p=0.023)$, and physically inactive $(\mathrm{OR}=1.86 ; p<0.001)$ were positively and significantly associated with "meat dietary pattern." Moreover, individuals with depression symptoms $(\mathrm{OR}=1.50 ; p=0.018)$ and the ones who did lower number of medical appointments in the previous year ( $\mathrm{OR}=0.98 ; p=0.025)$ were less likely to report this $\mathrm{DP}$.

Conclusion: Our results suggest that unhealthy DPs (meat DP) are part of a lifestyle behavior that includes physical inactivity, smoking habits, and alcohol consumption. Moreover, depression symptoms are also associated with unhealthy DPs.

Keywords: dietary patterns, lifestyles behaviors, health status, mental health, Portugal 


\section{INTRODUCTION}

Dietary factors and other lifestyles such as physical inactivity, tobacco use, and harmful ingestion of alcohol are well documented risk factors for several non-communicable chronic diseases (NCDs) and death (1). In fact, an inverse association of healthful dietary patterns (DPs) with all-cause mortality, cancer and cardiovascular disease risk was reported in several studies (2-6). Taking into account these trends in global health, World Health Organization (WHO) has established the prevention and control of NCDs as a major public health challenge, suggesting the need to strengthen the actions to reduce the modifiable risk factors (7). In Portugal, the leading risk factors for disease burden, measured in disability-adjusted life years (DALYs), are unhealthy dietary habits, accounting for $19.2 \%$ of all DALYs (8). In terms of dietary behaviors, an excessive consumption of energy, saturated fats, trans fats, sugar and salt and low consumption of vegetables, fruits, and whole grains are pointed to as the most important factors related to these leading causes of death, disease, and disability (9-14).

Improving populations' health requires epidemiological information on peoples' health and lifestyles to further develop and target suitable interventions to population groups at risk. Indeed, the inequality gap in NCDs and their risk factors highlight the need of studying the DPs, as well as, their association with socioeconomic and demographic factors, lifestyle behaviors, and health status of the population. Several studies have pointed out the existence of a social gradient in dietary habits, showing that inadequate DPs are more prevalent among individuals from lower socioeconomic status. Educational level, income, and occupation have been suggested as the main socioeconomic factors associated with dietary habits (15). Moreover, a large body of epidemiologic data showed that inadequate dietary habits commonly coexist with other unhealthy lifestyle behaviors (physical inactivity, smoking habits, and alcoholic habits) in the same groups of the population (16-22).

In fact, in Portugal, the lack of epidemiological information, valid and useful to support public health decision-making, mainly in terms of food consumption and its association with NCDs data is a reality. The major national population health surveys (health interview survey, serological survey, and food and nutrition survey) have been conducted on irregular basis and there are no recent data. There is an urgent need to obtain information regarding health-related behaviors of the Portuguese population, providing information related to its determinants (socioeconomic and demographic factors), associated factors, and its consequences for health. Interestingly, one of the aims of Portuguese National Program for the Promotion of Healthy Eating (23) is to collect updated data on food consumption and nutrition, mainly among vulnerable population to take actions toward better health indicators.

Therefore, studying the determinants of DPs is of utmost importance when developing public health policies, identifying population groups that most likely would benefit from those interventions (24). Indeed, the considerably high attributable risk of NCDs due to lifestyles highlights the need of studying the role of DPs in populations with different exposure ranges, according to socioeconomic and demographic factors. It is also important to determine the associations between DPs and other behavioral and clinical variables of interest, in order to better identify vulnerable populations (25).

This study aims to identify DP of Portuguese adults, to assess their socioeconomic, demographic, and lifestyle determinants, and to identify their impact on health.

\section{MATERIALS AND METHODS}

\section{The Portuguese Setting}

Portugal is a South-western European country. According to 2011 Census, the Portuguese resident population was 10,562,178 inhabitants, 8,000,000 out of them are adults. According to Nomenclature of Territorial Unit for Statistics (NUTS II), Portugal is divided into the following seven regions: Norte, Centro, Lisboa e Vale do Tejo, Alentejo, Algarve, Azores, and Madeira (Figure 1).

\section{Study Design and Participants}

A random sample representative of the adult Portuguese population was recruited to constitute the EpiDoC cohort. EpiDoC cohort was designed to study health determinants and outcomes, NCDs, and their impact on health resources consumption. In each evaluation, a nuclear questionnaire regarding socioeconomic, chronic diseases in particular rheumatic diseases, quality of life, and health consumption was applied and was repeated at every evaluation in order to gather longitudinal data. Moreover, each wave of evaluation had also specific and distinct questions regarding other several health and health-related issues that allow obtaining cross-sectional and longitudinal data from these population-based studies. At the first study (EpiDoC 1 or EpiReumaPt), the main goal was to determine the prevalence of rheumatic diseases and their burden in Portugal $(26,27)$. In EpiDoC 2, the main goal was to characterize lifestyles, health innovation, and social interactions.

All the participants in EpiDoC 1 assessment who signed the Informed Consent for further evaluations and those who provided their telephone number were enrolled in the cohort. Subjects unwilling to sign the Informed Consent, unable to speak Portuguese, or with an inability to answer the questionnaire were excluded (28). Regardless, a caregiver might have been the one answering the questionnaire. The flowchart of EpiDoC cohort is described in Figure 2.

\section{Data Collection}

The data collection was performed between March 26, 2013 and July 27, 2015. A trained research assistant team was responsible for collecting the data from these subjects, by telephone calling all the individuals. When a contact was not available, they attempted different moments (morning, afternoon, evening, and weekends) in order to accomplish a minimum of six attempts. 


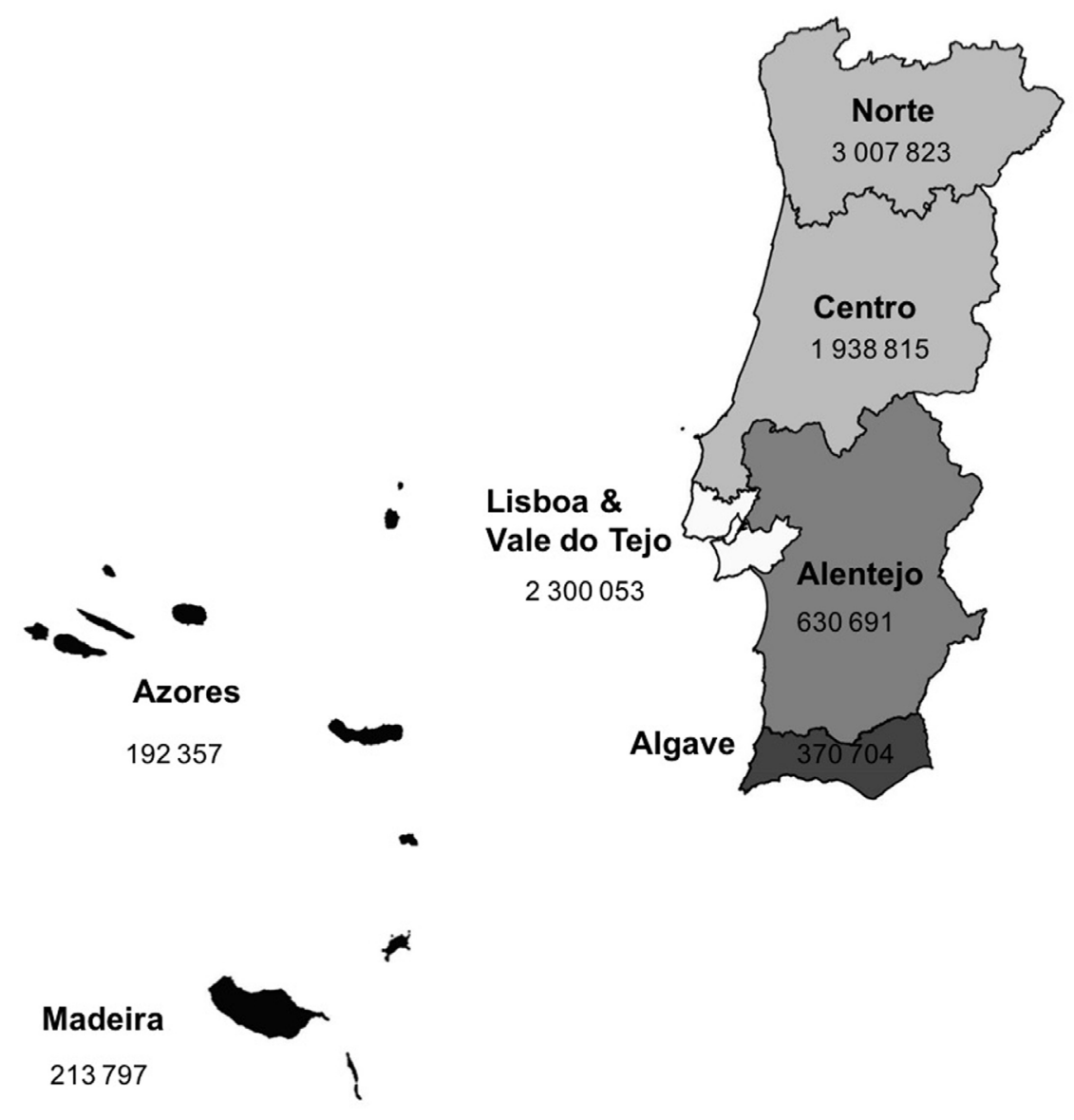

FIGURE 1 | Portugal population density distribution.

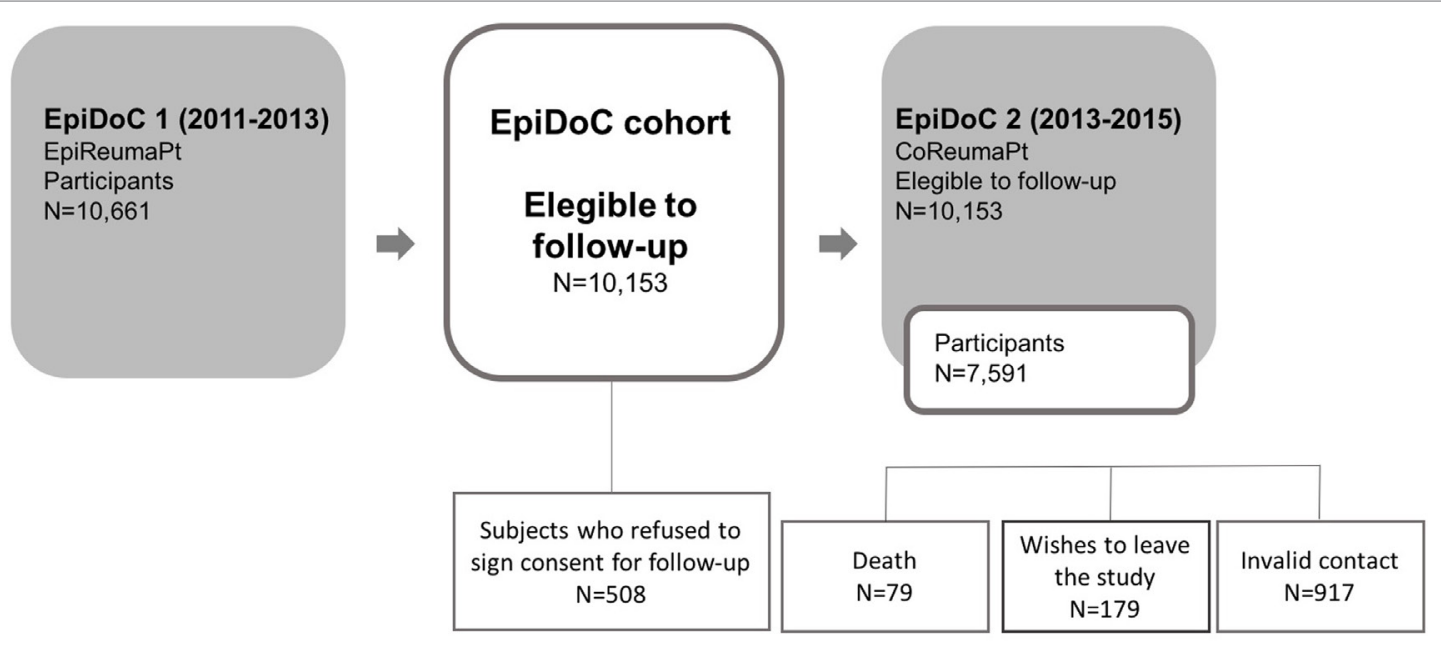

FIGURE 2 | Flowchart of EpiDoc study design.

The last contact had at least a 1-month interval from the previous one. Only then the contact is abandoned. Rescheduling of the phone interviews was an option.
The interview was telephonically performed with the assistance of a computer-assisted telephone interview system (an in-house software platform, developed by the informatics 
team of Sociedade Portuguesa de Reumatologia). Standardized procedures were undertaken to collect data.

\section{Measurements \\ Sociodemographic, Characteristics}

Sociodemographic (sex, age, ethnicity, years of education, marital status, household composition, and NUTS II) as well as socioeconomic variables (household income, employment status) were collected in EpiDoC 1 [EpiReumaPt study (26)]. At this second assessment (EpiDoC 2), subjects were asked whether there have been changes in those variables.

\section{Health Characteristics}

During EpiDoC 2 study, individuals were asked if they had been previously diagnosed with some chronic disease (high cholesterol level, high blood pressure, rheumatic disease, allergy, gastrointestinal disease, mental disease, cardiac disease, diabetes, thyroid and parathyroid disease, urolithiasis, pulmonary disease, hyperuricemia, cancer, neurologic disease, and hypogonadism). Health-related quality of life was assessed using the European Quality of Life questionnaire with five dimensions and three levels (EQ-5D-3L) $(29,30)$, where higher scores correspond to higher quality of life. Physical function was evaluated based on the Health Assessment Questionnaire (0-3, the higher the worse functional ability) (31). The Hospital Anxiety and Depression Scale (32) was applied to identify symptoms of anxiety and depression (score $>11$ ). All these assessment scales were Portuguesevalidated versions.

\section{Lifestyle Characteristics}

Self-reported height and weight were collected during EpiDoC 1 assessment. Body mass index (BMI, weight/height ${ }^{2}$, in $\mathrm{kg} / \mathrm{m}^{2}$ ) was calculated and categorized according to the WHO classification into four categories: underweight $\left(\mathrm{BMI}<18.5 \mathrm{~kg} / \mathrm{m}^{2}\right)$, normal (BMI between 18.5 and $24.9 \mathrm{~kg} / \mathrm{m}^{2}$ ), overweight (BMI between 25 and $29.9 \mathrm{~kg} / \mathrm{m}^{2}$ ) and obesity $\left(\mathrm{BMI} \geq 30 \mathrm{~kg} / \mathrm{m}^{2}\right)(33)$.

During EpiDoC 2 interview (2013-2015), questions concerning lifestyle habits were collected and included frequency of alcohol intake (daily, occasionally, never), quantity of alcohol units per week (less than or equal than three alcohol units per week; more than three alcohol units per week but less than three alcohol units per day; more than three alcohol units per day); smoking habits (daily, occasionally, past smoker, never smoked); frequency and type of physical activity; sleep habits (number of hours of sleep per day, categorized in $<6$ and $\geq 6 \mathrm{~h} /$ day); frequency of watching TV (categorized in does not watch, $\leq 2 \mathrm{~h} /$ day, 3-4 h/day, and $\geq 5 \mathrm{~h} /$ day) and frequency of use of computer/videogames/tablets (categorized in does not use, $\leq 2 \mathrm{~h} /$ day, 3-4 h/day, and $\geq 5 \mathrm{~h} /$ day). Physical activity level was classified based on the question related to the reported weekly frequency of physical activity, and three different categories of physical activity level were obtained according to the following criteria: inactive ( $<1 \mathrm{~h} /$ week), moderately active (between 1 and $2.5 \mathrm{~h} /$ week), and active ( $\geq 2.5 \mathrm{~h} /$ week).
Dietary intake was assessed through a group of questions, namely food frequency questions for the following foods and beverages: soup ${ }^{1}$, vegetables, fresh fruit, milk and other dairy products (Question: "How many times per week do you eat or drink...?" Categories of response: everyday, 6 times/week, 3-5 times/week, 1-2 times/week, rarely, and never), meat, and fish (Question: "How many meals of ... do you consume per week?” Categories of response: 10-14 meals/week, 7-10 meals/ week, 4-6 meals/week, 1-3 meals/week, rarely, and never). Questions regarding the dietary intake also included the number of meals per day $(2,3,4,5$, or more meals per day) and the amount of water daily consumed $(1-2,3-4,5-7,>7$ glasses of $150 \mathrm{~mL} /$ day).

\section{Statistical Analysis}

In order to guarantee the representativeness of the sample in relation to the Portuguese population (Mainland and Madeira and Azores islands), extrapolation weights were computed and used in further statistical analysis. These were obtained by calibrating the extrapolation weights originally designed for the EpiDoC 1 (EpiReumaPt) sample. We first compared the participants and non-participants of the EpiDoC 2 study, concerning their sociodemographic, socioeconomic, and health status characteristics. Based on this comparison, we adjusted the weights based on the stratification by NUT II region, sex, age group (resulting from the aggregation of the original classes in $18-35,36-55,56-65, \geq 66$ years in the Norte, Centro, and Lisboa regions, and $18-65, \geq 66$ years in Alentejo, Algarve, the Azores, and Madeira) (26).

Individuals were classified according to their DPs and two clusters were built based on dietary intake (number of meals, weekly frequency of consumption of soup, vegetables, fresh fruit, meat, fish, milk/dairy products, and water intake per day). The scales were very different among questions which implied standardization procedures by rescaling the variables to have a mean of zero and a SD of 1. For the cluster analysis, Ward's Linkage (34) was used with squared Euclidian distance (35). Of note, food pattern studies are already widely used in Nutritional Epidemiology, and Cluster analysis is one of the methods commonly adopted (36-39).

Since the original questions were recorded as categorical variables, a conversion was made with the purpose of obtaining continuous variables, appropriate for this analysis. A weekly consumption measure was created for each question, considering the middle point for each category.

For the number of meals, it was considered that the common maximum daily number of meals was 6 , and therefore, the last category (5 or more meals/day) was recoded using the middle point of 5.5 meals times per day for the 7 days of the week. Thus, the original categories of 2 meals/day, 3 meals/day, 4 meals/day and 5 or more meals/day were recoded, respectively, in the following weekly frequency $14,21,28$, and 38.5 .

${ }^{1}$ The question regarding the frequency of soup consumption did not specify that we are asking about the consumption of vegetable soup, however, "soups" in Portugal are traditionally prepared with vegetables. 
For the soup, vegetables, fruit, and milk/dairy products frequency of consumption, it was assumed that everyday consumption can range from once to twice a day, translating in 7-14 times a week, which results in a middle point of 10.5 times a week. For the rarely category, it was reasonable to consider a monthly frequency of consumption, being recoded using 0.25 (once a month -1 time in 4 weeks). Thus for these questions, the original categories of everyday, 6 times/week, 3-4 times/week, 1-2 times/week, rarely, and never were recoded, respectively, in the following weekly frequency $10.5,6,4,1.5$, 0.25 , and 0 .

For the frequency of consumption of meals of meat and fish, it was reasonable to consider a twice monthly based frequency of consumption for the rarely category, since for meat and fish, the question was related to the number of meals per week instead of number of times per week. The original categories of 10-14 meals/week, 7-10 meals/week, 4-6 meals/week, 1-3 meals/week rarely, and never were recoded, respectively, in the following weekly frequency $12,8.5,5,2,0.5$, and 0 .

For the highest category of water intake, it was considered the standard recommendation of up to $2 \mathrm{~L}$ per day, which translates into up to 14 glasses of $150 \mathrm{~mL}$ (approximately $2 \mathrm{~L}$ ), being the middle point 10.5 glasses per day, which correspond to the middle point of 73.5 glasses per week. The original categories of 1-2 glasses/day, 3-4 glasses/day, 5-7 glasses/day, and $>7$ glasses/day were recoded, respectively, in the following weekly frequency $10.5,24.5,42$, and $73.5 \mathrm{~mL}$.

Absolute frequencies and weighted proportions were used to summarize categorical variables. Continuous variables were described by weighted mean values and SDs.

Logistic regression models were used to assess the differences between the obtained clusters of DPs, regarding sociodemographic, socioeconomic, health status, and lifestyle variables. These models were always adjusted for sex, age, and NUT II. The associations between DPs and sociodemographic, socioeconomic, health status, and lifestyle variables were further investigated based on crude and adjusted (age, sex, education, employment status, NUT II, smoking habits, physical activity, and alcohol habits) models. Multivariable models were performed using backward selection. Results were described in terms of odds ratio (OR) and corresponding 95\% confidence intervals. Significance level was set at 0.05 . Possible interactions between variables introduced in the model that might be correlated were tested.

All analyses were weighted and performed using Stata IC version 12 (StataCorp. 2011. Stata Statistical Software: Release 12; StataCorp LP, College Station, TX, USA).

\section{Ethics}

The study of the subjects was performed according to the principles established by the Declaration of Helsinki (40) and revised in 2013 in Fortaleza. The study was reviewed and approved by the National Committee for Data Protection (Comissão Nacional de Proteção de Dados) and by the NOVA Medical School Ethics Committee. The participants provided written informed consent to contribute in all phases of the study.

\section{RESULTS}

In EpiDoC 2 study, a total of 7,591 participants completed the questionnaire. The EpiDoC cohort's sociodemographic characteristics did not differ from the Portuguese population (Table 1). Table 2 presents the dietary habits description of EpiDoC population.

TABLE 1 | Sociodemographic characteristics of the adult Portuguese population: EpiDoC 2 and Census 2011 (41) populations (Portuguese population).

\begin{tabular}{|c|c|c|}
\hline & $\begin{array}{c}\text { EpiDoC 2, } \\
n=7,591\end{array}$ & $\begin{array}{l}\text { Census 2011, } \\
n=8,657,240\end{array}$ \\
\hline \multicolumn{3}{|l|}{ Sex } \\
\hline Female & $4,784(52.2 \%)$ & $4,585,118(53.0 \%)$ \\
\hline Age (mean \pm SD) & $48.02(18.02)$ & $41.31(16.28)$ \\
\hline \multicolumn{3}{|l|}{ Age group } \\
\hline $18-29$ & $621(18.4 \%)$ & $1,470,782(17.0 \%)$ \\
\hline 30-39 & 975 (18.7\%) & $1,598,250(18.5 \%)$ \\
\hline $40-49$ & 1,437 (18.2\%) & $1,543,392(17.8 \%)$ \\
\hline $50-59$ & $1,437(16.2 \%)$ & $1,400,011(16.2 \%)$ \\
\hline $60-69$ & $1,440(13.2 \%)$ & $1,186,442(13.7 \%)$ \\
\hline $70-74$ & 645 (6.2\%) & 496, $438(5.7 \%)$ \\
\hline$\geq 75$ & $1,036(9.1 \%)$ & $961,925(11.1 \%)$ \\
\hline \multicolumn{3}{|l|}{ Ethnicity/race } \\
\hline Caucasian & 7,423 (97.1\%) & No comparable data \\
\hline Black & 119 (2.5\%) & \\
\hline Asian & $3(0.0 \%)$ & \\
\hline Gipsy & 7 (0.1\%) & \\
\hline Other & $22(0.3 \%)$ & \\
\hline Years of education (mean $\pm S D$ ) & $8.66(3.90)$ & No comparable data \\
\hline \multicolumn{3}{|l|}{ Education level } \\
\hline$>12$ years & $1,336(22.2 \%)$ & $1,741,567(20.1 \%)$ \\
\hline 10-12 years & $1,391(24.8 \%)$ & $1,560,958(18.0 \%)$ \\
\hline $5-9$ years & $1,547(21.3 \%)$ & $2,134,401(24.6 \%)$ \\
\hline $0-4$ years & $3,272(31.7 \%)$ & $3,239,724(37.4 \%)$ \\
\hline \multicolumn{3}{|c|}{ Nomenclature of Territorial Unit for Statistics } \\
\hline Norte & $2,240(35.8 \%)$ & $3,007,823(34.7 \%)$ \\
\hline Centro & $1,504(23.3 \%)$ & $1,938,815(22.4 \%)$ \\
\hline Lisboa & $1,588(25.4 \%)$ & $2,300,053(26.6 \%)$ \\
\hline Alentejo & $422(7.2 \%)$ & $633,691(7.3 \%)$ \\
\hline Algarve & $245(3.8 \%)$ & $370,704(4.3 \%)$ \\
\hline Azores & $793(2.1 \%)$ & $192,357(2.2 \%)$ \\
\hline Madeira & $799(2.4 \%)$ & $213,797(2.5 \%)$ \\
\hline \multicolumn{3}{|l|}{ Marital status } \\
\hline Single & $1,285(28.4 \%)$ & No comparable data \\
\hline Married & $4,591(53.2 \%)$ & \\
\hline Divorced & $556(6.8 \%)$ & \\
\hline Widow(er) & $910(7.3 \%)$ & \\
\hline Consensual union & $244(4.2 \%)$ & \\
\hline \multicolumn{3}{|l|}{ Household income } \\
\hline$<500 €$ & $1,331(18.0 \%)$ & No comparable data \\
\hline $501-750 €$ & $1,257(20.8 \%)$ & \\
\hline $751-1,000 €$ & $943(19.0 \%)$ & \\
\hline $1,001-1,500 €$ & $852(17.5 \%)$ & \\
\hline $1,501-2,000 €$ & $511(10.9 \%)$ & \\
\hline $2,001 €-2,500 €$ & $295(5.7 \%)$ & \\
\hline $2,501-3,000 €$ & $188(3.8 \%)$ & \\
\hline $3,001-4,000 €$ & $108(2.1 \%)$ & \\
\hline$>4,000 €$ & $73(2.2 \%)$ & \\
\hline
\end{tabular}

(Continued) 
TABLE 1 | Continued

\begin{tabular}{lcc}
\hline & $\begin{array}{c}\text { EpiDoC 2, } \\
\boldsymbol{n}=\mathbf{7 , 5 9 1}\end{array}$ & $\begin{array}{c}\text { Census 2011, } \\
\boldsymbol{n}=\mathbf{8 , 6 5 7 , 2 4 0}\end{array}$ \\
& $2.85(1.24)$ & No comparable data \\
$\begin{array}{l}\text { Household composition (mean } \pm \text { SD) } \\
\text { Household composition }\end{array}$ & $1,121(11.9 \%)$ & No comparable data \\
1 person & $2,710(32.1 \%)$ & \\
2 people & $1,901(27.9 \%)$ & \\
3 people & $1,859(28.2 \%)$ & \\
$\geq 4$ people & $236(2.9 \%)$ & No comparable data \\
Single-parent family & & \\
Employment status & $3,167(52.7 \%)$ & No comparable data \\
Employed full-time & $224(3.3 \%)$ & \\
Employed part-time & $643(4.7 \%)$ & \\
Domestic worker & $613(9.3 \%)$ & \\
Unemployed & $149(4.1 \%)$ & \\
Student & $145(1.6 \%)$ & \\
Temporally work disabled & $2,438(24.2 \%)$ & \\
Retired & &
\end{tabular}

Sample size is not constant due to missing data.

EpiDoc-ethnicity/race $(n=7,574)$, years of education $(n=7,573)$, education level $(n=7,546)$, marital status $(n=7,586)$, household income $(n=5,558)$, and employment status $(n=7,379)$.

Female-ethnicity/race $(n=4,776)$, years of education $(n=4,774)$, education level ( $n=4,759)$, marital status ( $n=4,781)$, household income $(n=3,514)$, employment status $(n=4,661)$.

Male-ethnicity/race ( $n=2,798)$, years of education $(n=2,799)$, education level $(n=2,787)$, marital status ( $n=2,805)$, household income $(n=2,044)$, employment status $(n=2,718)$.

18-64 years - ethnicity/race ( $n=5,185)$, years of education $(n=5,189)$, education level ( $n=5,184)$, marital status ( $n=5,195)$, household income $(n=3,779)$, and employment status $(n=5,103)$.

$\geq 65$ years - ethnicity/race $(n=2,389)$, years of education $(n=2,384)$, education level ( $n=2,362)$, marital status $(n=2,391)$, household income $(n=1,779)$, and employment status $(n=2,276)$.

\section{Dietary Patterns}

According to the study purpose, two clusters were identified: cluster 1 with 1,312 individuals and cluster 2 with 4,642 individuals. Cluster 1 was classified as "unhealthier" DP than cluster 2, considering the means of the standardized variables for weekly consumption for each cluster (Table 3). The comparison of such means by clusters allows us to observe that there is a clear difference between the groups, regarding the pattern of food consumption. Cluster 1 ("meat dietary pattern") has a reduced number of meals per week, less frequency of consumption of soup, vegetables, fresh fruit, fish, milk/dairy products, and less water intake. Cluster 1 has the higher frequency of consumption of meat. Cluster 2 ("Fruit \& vegetables dietary pattern") has a higher number of meals per week, high frequency of consumption of soup, vegetables, fresh fruit, fish, milk/dairy products, and high water intake. Cluster 2 has a lower frequency of consumption of meat.

\section{Sociodemographic and Lifestyle Characteristics Associated with "Meat Dietary Pattern"}

We performed logistic regression models in order to identify the associated factors with the "unhealthy" DP_-"meat dietary pattern" (Tables 4 and 5). We found that women compared to men $(\mathrm{OR}=0.52 ; p<0.001)$, people of higher age $(\mathrm{OR}=0.97$;
TABLE 2 | Description of dietary habits of the adult Portuguese population: EpiDoC 2.

EpiDoC 2, $n=7,591$

Number of meals
2 meals/day
3 meals/day
4 meals/day
5 or more meals/day

$341(5.5 \%)$

$2,239(33.7 \%)$

$1,921(33.5 \%)$

$1,566(27.2 \%)$

\section{Frequency of soup consumption}

Everyday

2,581 (39.8\%)

6 times/week

3-5 times/week

1-2 times/week

$247(3.0 \%)$

$1,540(24.0 \%)$

$965(17.7 \%)$

$573(12.0 \%)$

169 (3.4\%)

Never

$3,281(53.0 \%)$

$396(5.5 \%)$

$1,559(26.2 \%)$

$570(10.4 \%)$

$197(3.5 \%)$

$69(1.4 \%)$

Never

$4,697(76.1 \%)$

$160(1.9 \%)$

$705(12.7 \%)$

295 (5.5\%)

165 (3.0\%)

$46(0.9 \%)$

Never

1,022 (20.2\%)

$1,820(31.5 \%)$

1,683 (29.0\%)

1,367 (17.0\%)

$107(1.2 \%)$

51 (1.0\%)

206 (2.7\%)

$1,296(20.7 \%)$

$1,812(29.8 \%)$

2,485 (43.5\%)

$161(2.4 \%)$

$46(0.9 \%)$

$4,553(74.6 \%)$

$103(2.0 \%)$

575 (9.9\%)

333 (5.0\%)

$233(4.1 \%)$

266 (4.5\%)

Never

$755(10.7 \%)$

$1,522(23.5 \%)$

$2,038(35.1 \%)$

1,725 (30.8\%)
Sample size is not constant due to missing data.

EpiDoc-number of meals ( $n=6,067)$, frequency of soup consumption $(n=6,075)$, frequency of vegetables consumption $(n=6,072)$, frequency of fresh fruit consumption ( $n=6,068)$, frequency of meat consumption $(n=6,050)$, frequency of fish consumption ( $n=6,006)$, frequency of milk/diary products consumption $(n=6,063)$, and daily water intake $(n=6,040)$. 
TABLE 3 | Mean values of the padronized variables for weekly consumption for each cluster and for the entire population.

\begin{tabular}{lcrr}
\hline & $\begin{array}{c}\text { "Meat dietary } \\
\text { pattern" }\end{array}$ & $\begin{array}{c}\text { "Fruit \& } \\
\text { vegetables } \\
\text { dietary pattern" }\end{array}$ & Total \\
\hline Number of meals & -0.3077 & 0.0881 & 0.0009 \\
Soup consumption & -0.3179 & 0.0901 & 0.0002 \\
Vegetables consumption & -0.4800 & 0.1347 & -0.0007 \\
Fresh fruit consumption & -1.7850 & 0.5024 & -0.0016 \\
Meat consumption & 0.1531 & -0.0344 & 0.0069 \\
Fish consumption & -0.2877 & 0.0789 & -0.0019 \\
Dairy products consumption & -0.1839 & 0.0583 & 0.0050 \\
Water intake & -0.1331 & 0.0385 & 0.0007 \\
\hline
\end{tabular}

$p<0.001)$, and people with more years of education $(\mathrm{OR}=0.96$; $p=0.025)$ are less likely to adopt the meat DP. On the other hand, individuals in a situation of unemployment/part-time employment/domestic worker $(\mathrm{OR}=1.49 ; p=0.013)$ were more likely to adopt this DP than their counterparts (employed full-time/ student/temporally work disabled/retired). Individuals from Azores tend to be more prone to belong to this group ( $\mathrm{OR}=1.40$; $p=0.026$ vs Norte) (Table 4).

Inherently, some other lifestyle factors were significantly and independently associated with the adoption of the "meat dietary pattern," individuals who smoke (OR $=1.58$; $p<0.001)$, those who drink alcohol daily $(\mathrm{OR}=1.46 ; p=0.023)$, and those who are physically inactive $(\mathrm{OR}=1.86 ; p<0.001)$ seem to opt more for this DP. Furthermore, individuals who spend two or less hours per day using computers, videogames, and tablets $(\mathrm{OR}=0.75 ; p=0.043)$ were less likely to adopt the "meat dietary pattern" (Table 4).

\section{Health Characteristics Associated With "Meat Dietary Pattern"}

Regarding health status factors, we verified that the adoption of "meat dietary pattern" was significantly associated with depression symptoms $(\mathrm{OR}=1.50 ; p=0.018)$ (Table 5). Considering health-care resource consumption, individuals with a higher number of medical appointments since last contact $(\mathrm{OR}=0.98$; $p=0.025$ ) were less likely to adopt this DP (Table 5).

\section{Determinants of "Meat Dietary Pattern"}

In the end, we have constructed a final model to identify the independent factors that contribute for the adoption of "meat dietary pattern" in Portugal (Table 6). A situation of unemployment/part-time employment/domestic working was an independent determinant for the adoption of "meat dietary pattern" $(\mathrm{OR}=0.33 ; p=0.041)$. Female sex $(\mathrm{OR}=0.52 ; p<0.001)$, elderly $(\mathrm{OR}=0.97 ; p<0.001)$, and higher literacy $(\mathrm{OR}=0.96$; $p=0.040$ ) were considered protective factors for the adoption of "meat dietary pattern." Regional disparities were also verified, with living on the Azores ( $\mathrm{OR}=1.44 ; p=0.017$ ) and Madeira $(\mathrm{OR}=1.39 ; p=0.046)$ islands being independent determinants for the adoption of "lower fruit and vegetables intake and higher meat intake" DP. Regarding lifestyle factors, individuals who were current smokers $(\mathrm{OR}=1.50 ; p=0.003)$ and physically inactive $(\mathrm{OR}=1.80 ; p<0.001)$ had 50 and $80 \%$, respectively, higher odds of having a "meat dietary pattern." Finally, we found a negative association between self-reported diabetes and the adoption of a DP with a lower frequency of consumption of soup, vegetables, and fruit and a higher frequency of meat consumption $(\mathrm{OR}=0.72 ; p=0.035)$, while a positive association was found between depression symptoms $(\mathrm{OR}=1.56 ; p=0.010)$ and the adoption of this DP (Table 6).

\section{DISCUSSION}

Using a representative sample of the adult Portuguese population we identified two distinct DPs through cluster analysis, the "meat dietary pattern" and the "fruit \& vegetables dietary pattern." Similar results were also identified in other countries (using a posteriori defined DP), with higher scores on fruits, vegetables, and fish and lower scores in meat indicating a healthier DP (42). Our study has showed that the "unhealthy" DP ("meat dietary pattern") is independently associated with younger age, lower years of education, male sex, unemployment, part-time employment and domestic working. Furthermore, individuals from Azores and Madeira were more likely to report this kind of DP, given their high frequency of consumption of meat. Regarding lifestyle behaviors, smoking and being physically inactive were significantly and independently associated with having this type of DP.

The Portuguese third National Health Survey was performed 16 years ago. In this study, they also found that individuals with a higher education level reported to consume more frequently fruit, vegetables, milk and fish, and less wine and spirits than their counterparts from less educated groups. However, in contrast to our findings, the Portuguese third National Health Survey suggested that differences according to income were less clear, since there were no significant differences in food consumption between low and high income groups (43). The actual change can be justified by the worsening economic condition in the last 5 years in Portugal.

The inverse association between an unhealthy DP and socioeconomic status, namely with education and employment status, has been described across different studies in different populations $(20,44,45)$. In fact, sex and age were also observed to influence DPs. In general, men tend to have a higher frequency of meat consumption and a lower frequency of consumption of fruit and vegetables. Furthermore, the elderly tend to eat more frequently soup, vegetables, fruit, and fish and less frequently meat. These trends were observed in other studies $(19,21,46,47)$. Also, a recent analysis on DPs in the French population revealed that women were more concerned about healthy eating and that younger people were more likely to have unhealthier DPs. The influence of socioeconomic factors in diet was also confirmed in the DPs in France (48).

Geographical differences in dietary habits in Portugal were also observed. The regions of Madeira and Azores islands have a significant higher proportion of residents that have the unhealthy pattern. A higher prevalence of overweight and obesity was also found in Azores region. Geographical differences in DPs are not surprising since dietary habits are largely influenced by cultural, socioeconomic aspects, and local food availability $(25,49)$. 
TABLE 4 | Crude and adjusted odds ratio (OR) for the association between sociodemographic and lifestyle characteristics of "meat dietary pattern."

\begin{tabular}{|c|c|c|c|c|c|c|}
\hline & $\begin{array}{l}\text { "Meat dietary } \\
\text { pattern" }\end{array}$ & $\begin{array}{l}\text { "Fruit \& vegetables } \\
\text { dietary pattern" }\end{array}$ & $\begin{array}{c}\text { Crude OR (95\% } \\
\text { confidence interval, } \mathrm{Cl})\end{array}$ & $p$-Value & $\begin{array}{l}\text { Adjusted OR } \\
(95 \% \mathrm{Cl})\end{array}$ & $p$-Value \\
\hline \multicolumn{7}{|l|}{ SOCIODEMOGRAPHIC CHARACTERISTICS } \\
\hline \multicolumn{7}{|l|}{ Sex } \\
\hline Female & $646(37.5 \%)$ & $2,678(51.5 \%)$ & $0.57(0.46 ; 0.70)$ & $<0.001^{\dagger}$ & $0.52(0.40 ; 0.67)$ & $<0.001^{\dagger}$ \\
\hline Age & $41.31(16.28)$ & $48.30(17.99)$ & $0.98(0.97 ; 0.98)$ & $<0.001^{\dagger}$ & $0.97(0.96 ; 0.98)$ & $<0.001^{\dagger}$ \\
\hline Years of education & $9.20(3.58)$ & $8.78(3.89)$ & $1.03(1.00 ; 1.06)$ & $0.025^{\dagger}$ & $0.96(0.93 ; 0.99)$ & $0.025^{\dagger}$ \\
\hline \multicolumn{7}{|l|}{ Employment status } \\
\hline $\begin{array}{l}\text { Employed full-time/student/temporally work } \\
\text { disabled/retired }\end{array}$ & 1,022 (78.94\%) & $3,850(84.67 \%)$ & 1 & & 1 & \\
\hline $\begin{array}{l}\text { Unemployed/employed part-time/domestic } \\
\text { worker }\end{array}$ & $289(21.06 \%)$ & $778(15.33 \%)$ & $1.47(1.09 ; 1.99)$ & $0.011^{\dagger}$ & $1.49(1.09 ; 2.03)$ & $0.013^{\dagger}$ \\
\hline \multicolumn{7}{|l|}{ Marital status } \\
\hline Single/divorced/widow(er) & $543(50.6 \%)$ & $1,566(40.3 \%)$ & 1 & & 1 & \\
\hline Married/consensual union & $768(49.4 \%)$ & $3,071(59.7 \%)$ & $0.66(0.53 ; 0.82)$ & $<0.001^{\dagger}$ & $0.82(0.65 ; 1.03)$ & 0.084 \\
\hline Single-parent family & $55(3.54 \%)$ & $141(2.58 \%)$ & $1.39(0.93 ; 2.07)$ & 0.110 & $1.54(0.98 ; 2.41)$ & 0.060 \\
\hline \multicolumn{7}{|l|}{ NUTII } \\
\hline Norte & 448 (41.0\%) & $1,497(37.2 \%)$ & 1 & & 1 & \\
\hline Centro & $214(20.0 \%)$ & 1,055 (25.0\%) & $0.73(0.56 ; 0.94)$ & $0.013^{\dagger}$ & $0.78(0.60 ; 1.02)$ & 0.069 \\
\hline Lisboa & $239(24.1 \%)$ & 919 (23.9\%) & $0.92(0.66 ; 1.26)$ & 0.592 & $0.94(0.66 ; 1.34)$ & 0.742 \\
\hline Alentejo & $44(5.5 \%)$ & $234(6.6 \%)$ & $0.76(0.50 ; 1.15)$ & 0.191 & $0.77(0.49 ; 1.21)$ & 0.256 \\
\hline Algarve & 33 (3.4\%) & $136(3.6 \%)$ & $0.45(0.52 ; 1.38)$ & 0.507 & $0.79(0.47 ; 1.34)$ & 0.380 \\
\hline Azores & $172(3.0 \%)$ & $372(1.7 \%)$ & $1.65(1.25 ; 2.18)$ & $<0.001^{\dagger}$ & $1.40[(1.04 ; 1.89)]$ & $0.026^{+}$ \\
\hline Madeira & $162(3.1 \%)$ & $428(2.1 \%)$ & $1.36(1.00 ; 1.84)$ & 0.048 & $1.32(0.96 ; 1.83)$ & 0.092 \\
\hline \multicolumn{7}{|l|}{ LIFESTYLE CHARACTERISTICS } \\
\hline \multicolumn{7}{|l|}{ BMI $\left(\mathbf{k g} / \mathrm{m}^{2}\right)$} \\
\hline Underweight/normal weight & 567 (51.70\%) & $1,851(48.12 \%)$ & 1 & & 1 & \\
\hline Overweight/obesity & $674(48.30 \%)$ & $2,577(51.88 \%)$ & $0.87(0.69 ; 1.08)$ & 0.209 & $1.07(0.82 ; 1.40)$ & 0.603 \\
\hline \multicolumn{7}{|l|}{ Smoking habits } \\
\hline Never smoked/past smoker & 909 (61.53\%) & 3,864 (77.84\%) & 1 & & 1 & \\
\hline Current smoker & $403(38.47 \%)$ & 772 (22.16\%) & $2.20(1.69 ; 2.85)$ & $<0.001^{\dagger}$ & $1.58[(1.20 ; 2.09)]$ & $0.001^{\dagger}$ \\
\hline \multicolumn{7}{|l|}{ Alcohol intake } \\
\hline Never consumed & 403 (27.4\%) & $1,802(36.2 \%)$ & 1 & & 1 & \\
\hline Occasionally & $527(45.8 \%)$ & $1,650(40.4 \%)$ & $1.50(1.16 ; 1.93)$ & $0.002^{\dagger}$ & $1.17(0.87 ; 1.58)$ & 0.299 \\
\hline Daily & $473(34.5 \%)$ & $1,802(37.4 \%)$ & $1.51(1.14 ; 1.99)$ & $0.004^{\dagger}$ & $1.46(1.05 ; 2.02)$ & $0.023^{\dagger}$ \\
\hline \multicolumn{7}{|l|}{ SEDENTARY BEHAVIORS } \\
\hline \multicolumn{7}{|l|}{ Physical activity } \\
\hline Moderate/active & 401 (34.94\%) & $2,030(46.68 \%)$ & 1 & & 1 & \\
\hline Inactive & $897(65.06 \%)$ & $2,572(53.32 \%)$ & $1.63(1.29 ; 2.05)$ & $<0.001^{\dagger}$ & $1.86(1.45 ; 2.39)$ & $<0.001^{\dagger}$ \\
\hline \multicolumn{7}{|l|}{ Screen time-watching TV } \\
\hline Does not watch & $51(7.1 \%)$ & $122(3.1 \%)$ & 1 & & 1 & \\
\hline$\leq 2$ hours/day & 862 (63.5\%) & $3,112(70.1 \%)$ & $0.39(0.20 ; 0.76)$ & $0.005^{\dagger}$ & $0.47(0.21 ; 1.05)$ & 0.066 \\
\hline 3-4 h/day & $291(22.2 \%)$ & $1,011(19.9 \%)$ & $0.48(0.24 ; 0.96)$ & $0.038^{\dagger}$ & $0.65(0.29 ; 1.49)$ & 0.311 \\
\hline$\geq 5$ h/day & $105(7.2 \%)$ & $385(7.0 \%)$ & $0.44(0.18 ; 1.07)$ & 0.070 & $0.64(0.26 ; 1.59)$ & 0.336 \\
\hline \multicolumn{7}{|c|}{ Screen time-using computer/videogames/tablets } \\
\hline Does not use & $553(28.0 \%)$ & $2,080(35.0 \%)$ & 1 & & 1 & \\
\hline$\leq 2$ h/day & 415 (39.0\%) & $1,511(37.2 \%)$ & $1.31(1.00 ; 1.71)$ & $0.046^{\dagger}$ & $0.75(0.57 ; 0.99)$ & $0.043^{\dagger}$ \\
\hline 3-4 h/day & 107 (11.1\%) & $278(7.2 \%)$ & $1.93(1.25 ; 2.96)$ & $0.003^{\dagger}$ & $1.01(0.61 ; 1.68)$ & 0.972 \\
\hline$\geq 5$ h/day & $232(21.9 \%)$ & $763(20.6 \%)$ & $1.33(1.01 ; 1.75)$ & $0.042^{\dagger}$ & $0.81(0.54 ; 1.22)$ & 0.314 \\
\hline \multicolumn{7}{|l|}{ Sleep habits } \\
\hline$<6 \mathrm{~h} /$ day & $168(13.7 \%)$ & 495 (15.5\%) & 1 & & 1 & \\
\hline$\geq 6$ h/day & $654(86.3 \%)$ & $2,213(84.5 \%)$ & $0.87(0.64 ; 1.17)$ & 0.354 & $1.13(0.81 ; 1.60)$ & 0.470 \\
\hline \multicolumn{7}{|l|}{ Search for health information } \\
\hline Searchers vs non-searchers & $208(20.38 \%)$ & $1,014(27.88 \%)$ & $0.66(0.48 ; 0.92)$ & $0.013^{\dagger}$ & $0.73(0.51 ; 1.03)$ & 0.069 \\
\hline
\end{tabular}

Employment status was recoded as 0 if employed full-time/student/temporally work disabled/retired and 1 if unemployed/employed part-time/domestic worker; marital status was recoded as 0 if single/divorced/widow(er) and 1 if married/consensual union; household composition was considered as a continuous variable, giving the number of people in the household; body mass index (BMI) was recoded as 0 if underweight/normal weight and 1 if overweight/obesity; smoking habits was recoded as 0 if never smoked/past smoker and 1 if current smoker; physical activity was recoded as 0 if moderate/active and 1 if inactive; sleep habits was recoded as 0 if $<6$ h/day and 1 if $\geq 6$ h/day; search for health information was recoded as 0 if non-searchers and 1 if searchers.

Odds ratio adjusted for age, sex, education, employment status, NUTII, smoking habits, physical activity and alcohol habits. ${ }^{t} p$-Value $<0.05$. 
TABLE 5 | Crude and adjusted odds ratio (OR) for the association between health characteristics of "meat dietary pattern."

\begin{tabular}{|c|c|c|c|c|c|c|}
\hline & $\begin{array}{l}\text { "Meat dietary } \\
\text { pattern" }\end{array}$ & $\begin{array}{l}\text { "Fruit \& vegetables } \\
\text { dietary pattern" }\end{array}$ & $\begin{array}{c}\text { Crude OR ( } 95 \% \\
\text { confidence interval, } \mathrm{CI})\end{array}$ & $p$-Value & $\begin{array}{c}\text { Adjusted OR ( } 95 \% \\
\text { confidence interval, } \mathrm{Cl})\end{array}$ & $p$-Value \\
\hline \multicolumn{7}{|l|}{ Health characteristics } \\
\hline Number of NDCs (self-reported) & $1.18(1.47)$ & $1.66(1.84)$ & 0.83 (0.79; 0.88) & $<0.001^{\dagger}$ & $0.98(0.91 ; 1.05)$ & 0.506 \\
\hline \multicolumn{7}{|c|}{ Non-communicable chronic diseases (self-reported) } \\
\hline High blood pressure & $319(14.4 \%)$ & $1,448(24.5 \%)$ & $0.52(0.43 ; 0.63)$ & $<0.001^{\dagger}$ & $0.90(0.72 ; 1.13)$ & 0.375 \\
\hline Diabetes & $101(4.5 \%)$ & $540(9.3 \%)$ & $0.45(0.34 ; 0.61)$ & $<0.001^{\dagger}$ & $0.74(0.54 ; 1.00)$ & 0.055 \\
\hline High cholesterol level & $340(17.7 \%)$ & $1,459(25.7 \%)$ & $0.62(0.51 ; 0.76)$ & $<0.001^{\dagger}$ & $0.93(0.74 ; 1.15)$ & 0.490 \\
\hline Neoplastic disease & 40 (1.9\%) & $218(4.3 \%)$ & $0.41(0.26 ; 0.65)$ & $<0.001^{\dagger}$ & $0.56(0.31 ; 1.03)$ & 0.062 \\
\hline Quality of life EQ5D score & $0.81(0.25)$ & $0.79(0.27)$ & $1.52(1.05 ; 2.18)$ & $0.025^{\dagger}$ & $0.74(0.47 ; 1.19)$ & 0.218 \\
\hline $\begin{array}{l}\text { Physical function Health Assessment } \\
\text { Questionnaire score }(0-3)\end{array}$ & $0.23(0.45)$ & $0.32(0.54)$ & $0.71(0.60 ; 0.84)$ & $<0.001^{\dagger}$ & $1.13(0.95 ; 1.36)$ & 0.177 \\
\hline Anxiety symptoms (score $\geq 11$ ) & $200(10.7 \%)$ & 577 (10.8\%) & $0.99(0.76 ; 1.28)$ & 0.931 & $1.19(0.89 ; 1.61)$ & 0.240 \\
\hline Depression symptoms (score $\geq 11$ ) & 135 (6.3\%) & $398(6.5 \%)$ & $0.98(0.74 ; 1.29)$ & 0.867 & $1.50(1.07 ; 2.09)$ & $0.018^{\dagger}$ \\
\hline Was hospitalized since last contact & $171(10.4 \%)$ & 787 (15.8\%) & $0.62(0.47 ; 0.81)$ & $0.001^{\dagger}$ & $0.81(0.61 ; 1.08)$ & 0.144 \\
\hline $\begin{array}{l}\text { Number of medical appointments since } \\
\text { last contact }\end{array}$ & $4.97(5.40)$ & $6.32(6.80)$ & $0.96(0.94 ; 0.98)$ & $<0.001^{\dagger}$ & $0.98(0.96 ; 1.00)$ & $0.025^{\dagger}$ \\
\hline
\end{tabular}

OR adjusted for age, sex, education, employment status, NUTII, smoking habits, physical activity, and alcohol habits.

${ }^{t} p$-value $<0.05$.

TABLE 6 | Final multivariate model of the determinants of "meat dietary pattern."

Adjusted odds ratio (95\% $\quad p$-Value confidence interval, $\mathrm{Cl}$ )

\section{Sex}

Female

$0.52(0.41 ; 0.67)$

$<0.001^{\dagger}$

Age

$0.97(0.96 ; 0.98)$

$<0.001^{\dagger}$

Years of education

$0.96(0.93 ; 1.00)$

$0.040^{+}$

\section{Employment status}

Employed full-time/student/temporally

work disabled/retired

Unemployed/employed part-time/

domestic worker

NUTII

Norte

Centro

Lisboa

Alentejo

Algarve

Azores

Madeira

1

$1.33(1.01 ; 1.75)$

$0.041^{\dagger}$

$$
1
$$

$0.78(0.60 ; 1.03)$

$0.90(0.64 ; 1.27)$

$0.81(0.52 ; 1.27)$

$0.81(0.48 ; 1.38)$

$1.44(1.07 ; 1.95)$

$1.39(1.01 ; 1.93)$

\subsection{1 \\ 0.553 \\ 0.366 \\ 0.444 \\ $0.017^{\dagger}$ \\ $0.046^{\dagger}$}

Non-communicable chronic diseases (self-reported)

Diabetes

$0.72(0.53 ; 0.98) \quad 0.035^{\dagger}$

Depression symptoms (score $\geq 11$ )

$1.56(1.11 ; 2.19)$

$0.010^{\dagger}$

Smoking habits

Never smoked/past smoker

Current smoker

Physical activity

Moderate/active

Inactive

$1.80(1.41 ; 2.30) \quad<0.001^{\dagger}$

$n=5768, F_{(14,5,754)}=17.68, p<0.0001$.

Employment status was recoded as 0 if employed full-time/student/temporally work disabled/retired and 1 if unemployed/employed part-time/domestic worker; smoking habits was recoded as 0 if never smoked/past smoker and 1 if current smoker; physical activity was recoded as 0 if moderate/active and 1 if inactive.

${ }^{t} p$-Value $<0.05$

Furthermore, our study showed that unhealthy DPs, physical inactivity behaviors, smoking, and daily intake of alcohol coexist in the same individuals. These results were also observed in several other countries worldwide where unhealthy diet is combined with other unhealthy lifestyle behaviors such as physical inactivity, smoking and alcoholic habits (16-22). For instance, a recent study conducted in the English adult population showed that $68 \%$ of adults had at least two of the four unhealthy behaviors (unhealthy diet, physical inactivity, smoking, and heavy drinking) and that $26 \%$ had a combination of three or more of the four unhealthy behaviors (50). The results of an Irish population study are consistent with our findings, in which DPs are related to other lifestyles behaviors (physical activity and smoking) (51). Health promotion interventions are frequently focused on improving a specific lifestyle behavior. The co-occurrence of unhealthy behaviors in the same individuals suggests that health promotion interventions may be more effective if they focus on a multiple behavior approach than on a single behavior (22). In fact, several studies have demonstrated that the combination of diet and physical activity interventions has higher effect on weigh reduction and other health determinants (cholesterol levels and blood pressure) than when were performed alone. Moreover, these combined interventions also have demonstrated effect on smoking cessation. On the other hand, in subjects with alcohol addiction, treating more than one addiction including smoking will lead to a more sustained alcohol free period. These data reinforce the idea that public policies should focus on promoting multiple health behavioral change (52).

In terms of health outcomes, our study revealed that individuals with the "meat dietary pattern" reported depression symptoms more often. In line with our results, several studies have found that people who have an unhealthy diet were more likely to report symptoms of depression $(25,53-57)$. Indeed, several explanations can be pointed out for this result. There is some evidence suggesting that a healthy DP, with high intake of fruit, vegetables, whole grains, and fish, may reduce the depression risk. On the other hand, there is also evidence from observational studies that unhealthy diets, namely those with high contents of saturated fat and refined carbohydrates are identified as risk factors for 
depression. Furthermore, depression in elderly is associated with inability to shop for food and prepare meals (58).

We had tested the interactions between: diabetes and female sex; smokers and female sex; smokers and age; physical activity and female sex; physical activity and age; depression symptoms and female sex; and depression symptoms and age. For all the interactions tested we just found a significant association between depression symptoms and age $(\mathrm{OR}=1.02 ; p=0.04)$, as well as between depression symptoms and female sex $(\mathrm{OR}=2.36$; $p=0.013$ ). These significant interactions showed that the effect of the observed association between depression symptoms and "meat dietary pattern" is higher as age increases and in female individuals. These interactions were tested because several studies show that women and older individuals are more likely to have depression symptoms.

In our study, individuals with self-reported diabetes were less likely to report the "unhealthy" DP. One explanation could be that, since this is a cross-sectional study, it is possible that participants who had been previously diagnosed with diabetes might have modified their diet, which might explain this unexpected association. This finding might also be a result of social desirability bias in self-report data of dietary intake. In fact, several studies found that after a diagnosis of a chronic disease individuals tend to improve health-related behaviors (59-61).

We did not find associations between the "unhealthy dietary pattern" and overweight or obesity. One possible explanation for the absence of association between "unhealthy dietary pattern" and overweight or obesity could be the fact that our models were not adjusted for total energy intake (62) and/or some of the obese individuals are changing habits to decrease weight.

Our study has limitations that should be pointed out. It is important to highlight that the questions we used to assess dietary intake are limited to a few number of food groups. Thus, we are not able to look at these DPs as a whole. Although in our study we did not use the recommended methods to evaluate food consumption, the DPs found in our study are similar to those found in other studies of DPs analysis, namely in terms of food content of fruit, vegetables, and meat $(63,64)$. To examine the association between food consumption, socioeconomic factors, lifestyle behaviors, and health outcomes we used a DP approach (a posteriori defined DPs), which has the advantage to take into account the synergistic effects of the different nutrients and foods. Eating behavior is a complex issue and its evaluation requires the utilization of relative complex methods to assess food consumption. As a matter of fact, WHO suggested that in nutritional epidemiologic studies, population food consumption should be based on eating patterns $(42,65,66)$. Besides, according to a study conducted to analyze the validity and reproducibility of a posteriori DPs using food consumption data collected by two distinct methods (food frequency questionnaire and 24-h recall), two DPs similar to those that we found in our study were also found: "fruit and vegetables" DP and "meat" DP. This suggests a reasonable reproducibility of the DPs derived from the different method used to assess food consumption (64). Other limitation is the cross-sectional design, where causal associations are unable to be identified.
However, to our knowledge, these data are a major contribution for the understanding of the Portuguese dietary habits since there are no updated data regarding food consumption in a national representative population for Portugal. To our knowledge, this is the first study addressing the associations between DPs, socioeconomic status, lifestyle behaviors, and health outcomes, conducted in a large sample representative for the Portuguese population.

In conclusion, this study has identified diet vulnerable strata (male, young age, lower years of education, unemployment, part-time employment, domestic working, and island residents) among Portuguese adults. Moreover, unhealthy DP characterized by a lower frequency of consumption of soup, vegetables, fruit, fish, milk/dairy, less water intake, and a higher frequency of consumption of meat was significantly associated with depression symptoms. Strategies to promote fruit and vegetables consumption [at least $400 \mathrm{~g}$ per day in order to achieve WHO recommendations (67)] and assure the adequate intake of dairy products (2-3 portions per day in order to meet Portuguese food guide) and meat (37.5-112.5 g per day in order to meet Portuguese food guide) (68) must be a priority of public health policies.

Finally, unhealthy DPs are associated with other unhealthy lifestyle behaviors, such as physical inactivity, smoking, and alcoholic habits, which reinforces the idea that behavioral changes interventions should target more than one lifestyle domain (eat habits, physical exercise, alcohol, and smoking habits) (69).

Health education and multiple health behavioral change programs should start immediately among Portuguese vulnerable strata in order to improve their health status.

\section{ETHICS STATEMENT}

The study of the subjects was performed according to the principles established by the Declaration of Helsinki (40) and revised in 2013 in Fortaleza. The study was reviewed and approved by the National Committee for Data Protection (Comissão Nacional de Proteção de Dados) and by the NOVA Medical School Ethics Committee. The participants provided written informed consent to contribute in all phases of the study.

\section{AUTHOR CONTRIBUTIONS}

MG and AR contributed equally to this work. HC and AR designed the study. ME and AR analyzed the data. MG and AR interpreted the data and wrote the paper. JB, PG, PC, JM, RS, BA, KG, GE, and $\mathrm{HC}$ gave scientific support and revised the manuscript. All the authors discussed the results and implications and commented the manuscript at all stages.

\section{FUNDING}

The present project was granted by the Public Health Initiatives Programme (PT06), financed by EEA Grants Financial Mechanism 2009-2014. 


\section{REFERENCES}

1. Kant AK. Dietary patterns and health outcomes. J Am Diet Assoc (2004) 104(4):615-35. doi:10.1016/j.jada.2004.01.010

2. Trichopoulos A, Kouris-Blazos A, Wahlquist ML, Gnardelis C, Lagiou P, Polychronopoulos E, et al. Diet and overall survival in elderly people. BMJ (1995) 311:1457-60. doi:10.1136/bmj.311.7018.1457

3. Gerber MJ, Scali JD, Michaud A, Durand MD, Astre CM, Dallongeville J, et al. Profiles of a healthful diet and its relationship to biomarkers in a population sample from Mediterranean southern France. J Am Diet Assoc (2000) 100:1164-71. doi:10.1016/S0002-8223(00)00340-0

4. Kant AK, Schatzkin A, Graubard BI, Schairer C. A prospective study of diet quality and mortality in women. JAMA (2000) 283:2109-15. doi:10.1001/ jama.283.16.2109

5. McCullough ML, Feskanich D, Rimm EB, Giovannucci EL, Ascherio A, Variyam JN, et al. Adherence to the dietary guidelines for Americans and risk of major chronic diseases in men. Am J Clin Nutr (2000) 72:1223-31.

6. Osler M, Andreasen AH, Heitmann B, Hoidrup S, Gerdes U, Jorgenson LM, et al. Food intake patterns and risk of coronary heart disease: a prospective cohort study examining the use of traditional scoring techniques. Eur J Clin Nutr (2002) 56:568-74. doi:10.1038/sj.ejcn.1601360

7. World Health Organization. Global Status Report on Noncommunicable Diseases 2014. Geneva: World Health Organization (2014).

8. Direção-Geral da Saúde. A Saúde dos Portugueses. Perspectivas 2015. Lisboa: Direção-Geral da Saúde (2015).

9. Smith GD, Brunner E. Socio-economic differentials in health: the role of nutrition. Proc Nutr Soc (1997) 56:75-90. doi:10.1079/PNS19970011

10. Turrell G, Kavanagh AM. Socio-economic pathways to diet: modelling the association between socio-economic position and food purchasing behaviour. Public Health Nutr (2005) 9(3):375-83. doi:10.1079/PHN2006850

11. Tiffin R, Salois M. Inequalities in diet and nutrition. Proc Nutr Soc (2012) 71(1):105-11. doi:10.1017/S0029665111003284

12. Roberts KCN, Hancock C, Rutter H. Social and Economic Inequalities in Diet and Physical Activity. Oxford: Public Health England (2013).

13. World Health Organization Regional Office for Europe. WHO European Region Food and Nutrition Action Plan 2014-2020. Copenhagen (2013).

14. World Health Organization Regional Office for Europe. Vienna Declaration on Nutrition and Noncommunicable Diseases in the Context of Health 2020. Vienna, Austria (2013).

15. Darmon N, Drewnowski A. Does social class predict diet quality? Am Soc Clin Nutr (2008) 87(5):1107-17.

16. Kerver JM, Yang EJ, Bianchini L, Song WO. Dietary patterns associated with risk factors for cardiovascular disease in healthy US adults. Am J Clin Nutr (2003) 78:1103-10.

17. Sánchez-Villegas A, Delgado-Rodríguez $M$, Martinez-Gonzáles $M$, Irala-Estévez J. Gender, age, socio-demographic and lifestyle factors associated with major dietary patterns in the Spanish Project SUN (Seguimiento Universidad de Navarra). Eur J Clin Nutr (2003) 57:285-92. doi:10.1038/ sj.ejcn. 1601528

18. Deshmukh-Taskar PR, O’Neil CE, Nicklas TA, Yang SJ, Liu Y, Gustat J, et al. Dietary patterns associated with metabolic syndrome, sociodemographic and lifestyle factors in young adults: the Bogalusa Heart Study. Public Health Nutr (2009) 12(12):2493-503. doi:10.1017/s1368980009991261

19. Lenz A, Olinto MT, Dias-da-Costa JS, Alves AL, Balbinotti M, Pattussi MP, et al. Socioeconomic, demographic and lifestyle factors associated with dietary patterns of women living in Southern Brazil. Cad Saude Publica (2009) 25(6):1297-306. doi:10.1590/S0102-311X2009000600012

20. Mullie P, Clarys P, Hulens M, Vansant G. Dietary patterns and socioeconomic position. Eur J Clin Nutr (2010) 64(3):231-8. doi:10.1038/ejcn.2009.145

21. Olinto MT, Willett WC, Gigante DP, Victora CG. Sociodemographic and lifestyle characteristics in relation to dietary patterns among young Brazilian adults. Public Health Nutr(2011) 14(1):150-9. doi:10.1017/s136898001000162x

22. Héroux M, Janssen I, Lee D-C, Sui X, Hebert JR, Blair SN. Clustering of unhealthy behaviors in the aerobics center longitudinal study. Prev Sci (2012) 13(2):183-95. doi:10.1007/s11121-011-0255-0

23. Graça P, Gregório MJ. The construction of the national program for the promotion of healthy eating - conceptual aspects, strategic guidelines and initial challenges. Revista Nutrícias (2013) 18:6-9.
24. National Research Council Committee on Die and Health. Diet and Health: Implications for Reducing Chronic Disease Risk. Washington, DC: National Academies Press (US) Copyright (c) 1989 by the National Academy of Sciences (1989).

25. André B, Canhão H, Espnes GA, Rodrigues AMF, Gregorio MJ, Nguyen C, et al. Is there an association between food patterns and life satisfaction among Norway's inhabitants ages 65 years and older? Appetite (2017) 110:108-15. doi:10.1016/j.appet.2016.12.016

26. Rodrigues AM, Gouveia N, da Costa LP, Eusebio M, Ramiro S, Machado P, et al. EpiReumaPt- the study of rheumatic and musculoskeletal diseases in Portugal: a detailed view of the methodology. Acta Reumatol Port (2015) 40(2):110-24.

27. Branco JC, Rodrigues AM, Gouveia N, Eusebio M, Ramiro S, Machado PM, et al. Prevalence of rheumatic and musculoskeletal diseases and their impact on health-related quality of life, physical function and mental health in Portugal: results from EpiReumaPt- a national health surve. RMD Open (2016) 2(1):e000166. doi:10.1136/rmdopen-2015-000166

28. Laires PA, Canhão H, Araújo D, Fonseca JE, Machado P, Mourão AF, et al. CoReumaPt protocol: the Portuguese cohort of rheumatic diseases. Acta Reumatol Port (2012) 37:18-24.

29. Ferreira LN, Ferreira PL, Pereira LN, Oppe M. EQ-5D Portuguese population norms. Qual Life Res (2014) 23(2):425-30. doi:10.1007/s11136-013-0488-4

30. Ferreira LN, Ferreira PL, Pereira LN, Oppe M. The valuation of the EQ-5D in Portugal. Qual Life Res (2014) 23(2):413-23. doi:10.1007/s11136-013-0448-z

31. Fries JF, Spitz P, Kraines RG, Holman HR. Measurement of patient outcome in arthritis. Arthritis Rheum (1980) 23(2):137-45. doi:10.1002/art.1780230202

32. Pais-Ribeiro J, Silva I, Ferreira T, Martins A, Meneses R, Baltar M. Validation study of a Portuguese version of the Hospital Anxiety and Depression Scale. Psychol Health Med (2007) 12(2):225-35. doi:10.1080/13548500500524088

33. World Health Organization. Physical Status: the Use and Interpretation of Anthropometry Report of a WHO Expert Committee. WHO Technical Report Series 854. Geneva: World Health Organization (1995).

34. Ward JHJ. Hierarchical grouping to optimize an objective function. J Am Stat Assoc (1963) 58:236-44. doi:10.1080/01621459.1963.10500845

35. Everitt BS, Landau S, Leese M. Cluster Analysis. London: A member of the Hodder Headline Group (2001)

36. Wirfält E, Mattisson I, Gullberg B, Berglund G. Food patterns defined by cluster analysis and their utility as dietary exposure variables: a report from the Malmö Diet and Cancer Study. Public Health Nutr (2000) 3(2):159-73. doi:10.1017/S1368980000000197

37. Bamia C, Orfanos P, Ferrari P, Overvad K, Hundborg HH, Tjønneland A, et al. Dietary patterns among older Europeans: the EPIC-Elderly study. Br J Nutr (2005) 94(01):100. doi:10.1079/BJN20051456

38. Schulze MB, Hoffmann K. Methodological approaches to study dietary patterns in relation to risk of coronary heart disease and stroke. Br J Nutr (2006) 95(5):860-9. doi:10.1079/BJN20061731

39. Hearty ÁP, Gibney MJ. Comparison of cluster and principal component analysis techniques to derive dietary patterns in Irish adults. Br J Nutr (2009) 101(04):590. doi:10.1017/S0007114508014128

40. World Medical Association. World medical association declaration of Helsinki ethical principles for medical research involving human subjects. JAMA (2013) 310(20):2191-4. doi:10.1001/jama.2013.281053

41. Instituto Nacional de Estatística. Censos 2011: resultados definitivos-Portugal. Lisbon: Instituto Nacional de Estatística (2012).

42. World Health Organization. Report of a Joint FAO/WHO Consultation. Preparation and Use of Food-Based Dietary Guidelines. Geneva: World Health Organization (1998).

43. Moreira PA, Padrão P. Educational and economic determinants of food intake in Portuguese adults: a cross-sectional survey. BMC Public Health (2004) 4(58):1186-471. doi:10.1186/1471-2458-4-58

44. Dynesen AW, Haraldsdottir J, Holm L, Astrup A. Sociodemographic differences in dietary habits described by food frequency questions - results from Denmark. Eur J Clin Nutr (2003) 57:1586-97. doi:10.1038/sj.ejcn.1601728

45. Kant AK, Graubard BI. Secular trends in the association of socio-economic position with self-reported dietary attributes and biomarkers in the US population: National Health and Nutrition Examination Survey (NHANES) 1971-1975 to NHANES 1999-2002. Public Health Nutr (2007) 10:158-67. doi:10.1017/S1368980007246749 
46. Mishra G, Ball K, Arbuckle J, Crawford D. Dietary patterns of Australian adults and their association with socioeconomic status: results from the 1995 National Nutrition Survey. Eur J Clin Nutr (2001) 56:687-93. doi:10.1038/ sj.ejcn. 1601391

47. Park SY, Murphy SP, Wilkens LR, Yamamoto JF, Sharma S, Hankin JH, et al. Dietary patterns using the food guide pyramid groups are associated with sociodemographic and lifestyle factors: The Multiethnic Cohort Study. J Nutr (2005) 135:843-9.

48. Bertin M, Touvier M, Dubuisson C, Dufour A, Havard S, Lafay L, et al. Dietary patterns of French adults: associations with demographic, socio-economic and behavioural factors. J Hum Nutr Diet (2016) 29(2):241-54. doi:10.1111/jhn.12315

49. Quandt SA. Social and cultural influences on food consumption and nutritional status. 9th ed. In: Shils ME, Olson JA, Shike M, Ross AC, editors. Modern Nutrition in Health and Disease. New York: NK: Lippincott Williams and Wilkins (1999). p. 1783-92.

50. Poortinga W. The prevalence and clustering of four major lifestyle risk factors in an English adult population. Prev Med (2007) 44(2):124-8. doi:10.1016/j. ypmed.2006.10.006

51. Villegas R, Salim A, Collins MM, Flynn A, Perry IJ. Dietary patterns in middle-aged Irish men and women defined by cluster analysis. Public Health Nutr (2004) 7(8):1017-24. doi:10.1079/PHN2004638

52. Prochaska JJ, Prochaska JO. A review of multiple health behavior change interventions for primary prevention. Am J Lifestyle Med (2011) 5(3). doi:10.1177/1559827610391883

53. Lopresti AL, Hood SD, Drummond PD. A review of lifestyle factors that contribute to important pathways associated with major depression: diet, sleep and exercise. J Affect Disord (2013) 148(1):12-27. doi:10.1016/j.jad.2013.01.014

54. Lai JS, Hiles S, Bisquera A, Hure AJ, McEvoy M, Attia J. A systematic review and meta-analysis of dietary patterns and depression in community-dwelling adults. Am J Clin Nutr (2014) 99(1):181-97. doi:10.3945/ajcn.113.069880

55. Rahe C, Unrath M, Berger K. Dietary patterns and the risk of depression in adults: a systematic review of observational studies. Eur J Nutr (2014) 53(4):997-1013. doi:10.1007/s00394-014-0652-9

56. Opie RS, O'Neil A, Itsiopoulos C, Jacka FN. The impact of whole-of-diet interventions on depression and anxiety: a systematic review of randomised controlled trials. Public Health Nutr (2015) 18(11):2074-93. doi:10.1017/ s1368980014002614

57. Martinez-Gonzalez MA, Sanchez-Villegas A. Food patterns and the prevention of depression. Proc Nutr Soc (2016) 75(2):139-46. doi:10.1017/ s0029665116000045

58. Anyanwu UO, Sharkey JR, Jackson RT, Sahyoun NR. Home food environment of older adults transitioning from hospital to home. J Nutr Gerontol Geriatr (2011) 30(2):105-21. doi:10.1080/21551197.2011.566525

59. Pinto BM, Eakin E, Maruyama NC. Health behavior changes after a cancer diagnosis: what do we know and where do we go from here? Ann Behav Med (2000) 22:38-52. doi:10.1007/BF02895166
60. Patterson RE, Neuhouser ML, Hedderson MM, Schwartz SM, Standish LJ, Bowen DJ. Changes in diet, physical activity, and supplement use among adults diagnosed with cancer. J Am Diet Assoc (2003) 103:323-8. doi:10.1053/ jada.2003.50045

61. Wallstrom P, Mattisson I, Tyden P, Berglund G, Janzon L. Dietary habits after myocardial infarction - results from a cross-sectional study. J Intern Med (2005) 257:329-37. doi:10.1111/j.1365-2796.2005.01461.x

62. Rhee JJ, Cho E, Willett WC. Energy-adjustment of nutrient intakes is preferable to adjustment using body weight and physical activity in epidemiologic analyses. Public Health Nutr (2014) 17(5):1054-60. doi:10.1017/ S1368980013001390

63. Brantsaeter AL, Haugen M, Samuelsen SO, Torjusen H, Trogstad L, Alexander J, et al. A dietary pattern characterized by high intake of vegetables, fruits, and vegetable oils is associated with reduced risk of preeclampsia in nulliparous pregnant Norwegian women. J Nutr (2009) 139(6):1162-8. doi:10.3945/ jn.109.104968

64. Funtikova AN, Benítez-Arciniega AA, Fitó M, Schröder H. Modest validity and fair reproducibility of dietary patterns derived by cluster analysis. Nutr $\operatorname{Rev}(2015)$ 35(3):265-8. doi:10.1016/j.nutres.2014.12.011

65. Newby PK, Tucker KL. Empirically derived eating patterns using factor or cluster analysis: a review. Nutr Rev (2004) 62(5):177-203. doi:10.111 1/j.1753-4887.2004.tb00040.x

66. Fahey MT, Thane CW, Bramwell GD, Coward WA. Conditional Gaussian mixture modelling for dietary pattern analysis. JR Stat Soc (2007) 170(1): 149-66. doi:10.1111/j.1467-985X.2006.00452.x

67. World Health Organization. Healthy Diet, Fact sheet No. 394. Geneva: WHO (2015).

68. Rodrigues SSP, Franchini B, Graça P, Almeida MDVD. A new food guide for the Portuguese population: development and technical considerations. J Nutr Educ Behav (2006) 38:189-95. doi:10.1016/j.jneb.2006.01.011

69. Prochaska JO, DiClemente CC, Norcross JC. In search of how people change: applications to the addictive behaviors. Am Psychol (1992) 47:1102-14. doi:10.1037/0003-066X.47.9.1102

Conflict of Interest Statement: The authors declare that the research was conducted in the absence of any commercial or financial relationships that could be construed as a potential conflict of interest.

Copyright (C) 2017 Gregório, Rodrigues, Eusébio, Sousa, Dias, André, Grønning, Coelho, Mendes, Graça, Espnes, Branco and Canhão. This is an open-access article distributed under the terms of the Creative Commons Attribution License (CC BY). The use, distribution or reproduction in other forums is permitted, provided the original author(s) or licensor are credited and that the original publication in this journal is cited, in accordance with accepted academic practice. No use, distribution or reproduction is permitted which does not comply with these terms. 